\title{
Demystifying the potential of Global surgery for Public health
}

\author{
Parth Patel $^{1 *}$, Usman Garba Kurmi ${ }^{2}$, Hadiza Abubakar Balkore ${ }^{2}$, Dattatreya Mukherjee ${ }^{3}$ \\ ${ }^{1 *}$ H. K. College of Pharmacy, Jogeshwari West, Mumbai-400101, Maharashtra, India \\ ${ }^{2}$ Faculty of Science, Department of Biochemistry, University of Maiduguri, Africa \\ ${ }^{3}$ Jinan University, Guangzhou, P.R China \\ *Correspondence details: parth.patel@ hkcp.edu.in \\ Tel no: +91 7303105334
}

\begin{abstract}
:
Remarkable gains have been made in global health in the last 25 years, and surgical care is an integral component of healthcare systems for countries at all levels of development. Global surgery, which global surgery, which comprises clinical, educational, and research collaborations to improve surgical care between academic surgeons in high-income countries and low- and middle-income countries (LMICs) and their affiliated academic institutions, has grown significantly. Global surgery may resonate most with those in low-or-middle-income countries (LCMICs), where basic surgery needs are rarely met, and even the most trivial resource may be hard to obtain on a permanent or reliable basis. Therefore, considering this, this article provides an overview on various factors defining the interface between surgery and public health at a global level and discuss future directions.
\end{abstract}

\section{Introduction}

Global surgery, the 'enterprise of providing improved and equitable surgical care to the world's population', has garnered increasing attention over the last two decades. By glancing a view on fig 1, it can evidently be seen that global surgery has received significant amount of attention since last two decades. Global surgery is a new academic field developed in conjunction with numerous policy and advocacy initiatives. However, an estimated of 5 billion people worldwide lack timely access to safe and affordable surgical care, and 143 million surgical procedures worldwide are required to make up this shortfall. Global surgery should also be evaluated and conducted in a manner that ensures sustainability and an appropriate transfer of knowledge and skill. (Farmer PE and Kim JY, 2008). The global academic operation will be critical in that sense to measure progress in improving worldwide surgical care (Lavy $\mathrm{C}$, Sauven K, Mkandawire N, et al. 2011). However, the quality of the work emerging from this field must be rigorous as a new academic discipline (Citron I and Meara JG, 2019). Numerous university and policy stimuli, particularly the Lancet Commission for Global Surgery (Meara JG, Hagander L, and Leather AJM, 2014) and the increased global burden of noncommunicable illnesses were the consequence of the evolving interface between Surgery, Anesthesia, Public Health, and Global Health, many of which require Surgical Administration (Lim SS, Vos T, Flaxman AD, et al. 2012). Therefore, this article shall discuss various aspects of global surgery beginning with the need, workforce, Training and Education in Global 
Surgery, followed by access, quality, role of National and International Bodies, current situation and finally future aspects are discussed (Fig 2).

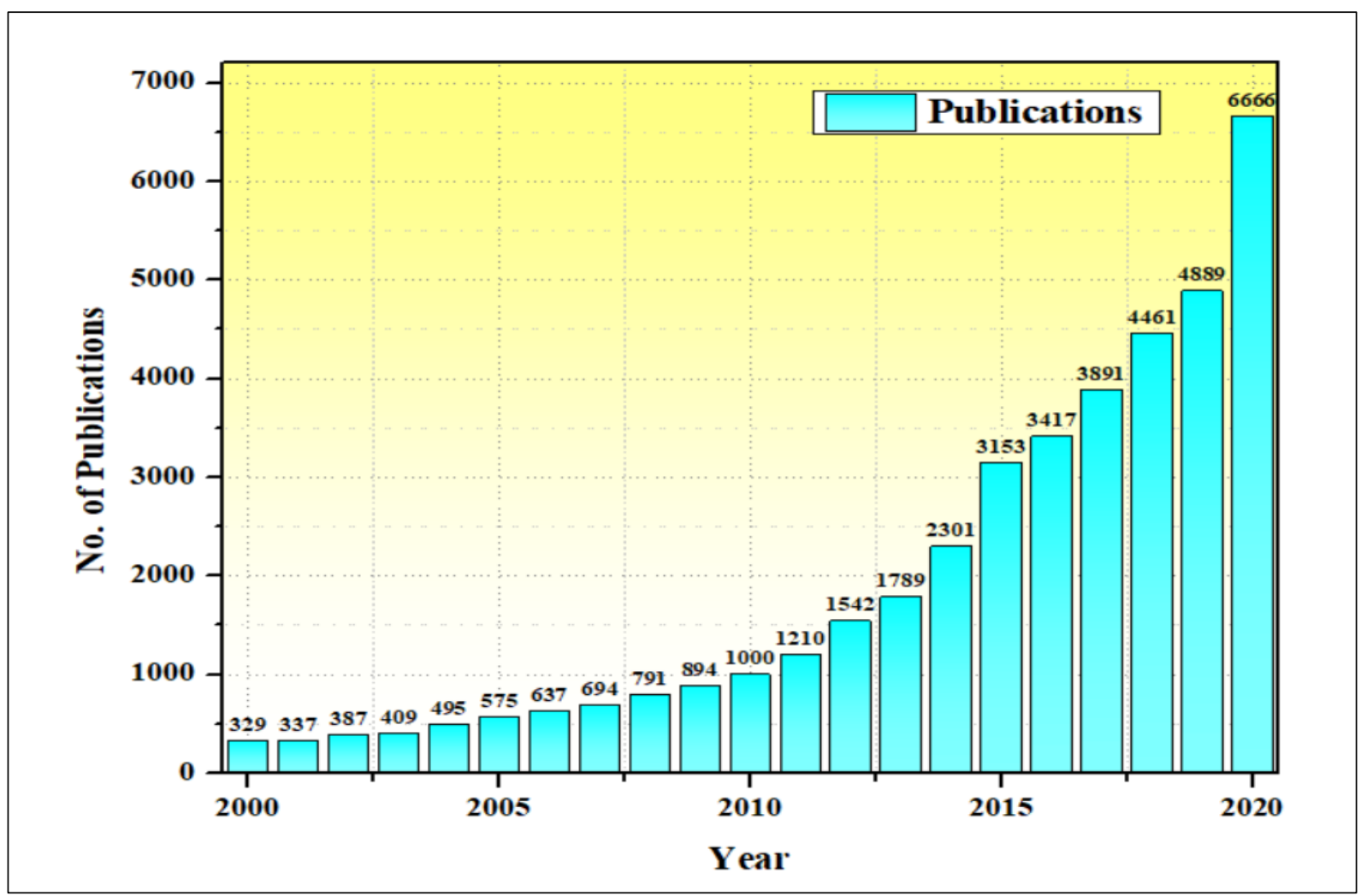

Fig 1: Number of publication on Global surgery (Source: PubMed database)

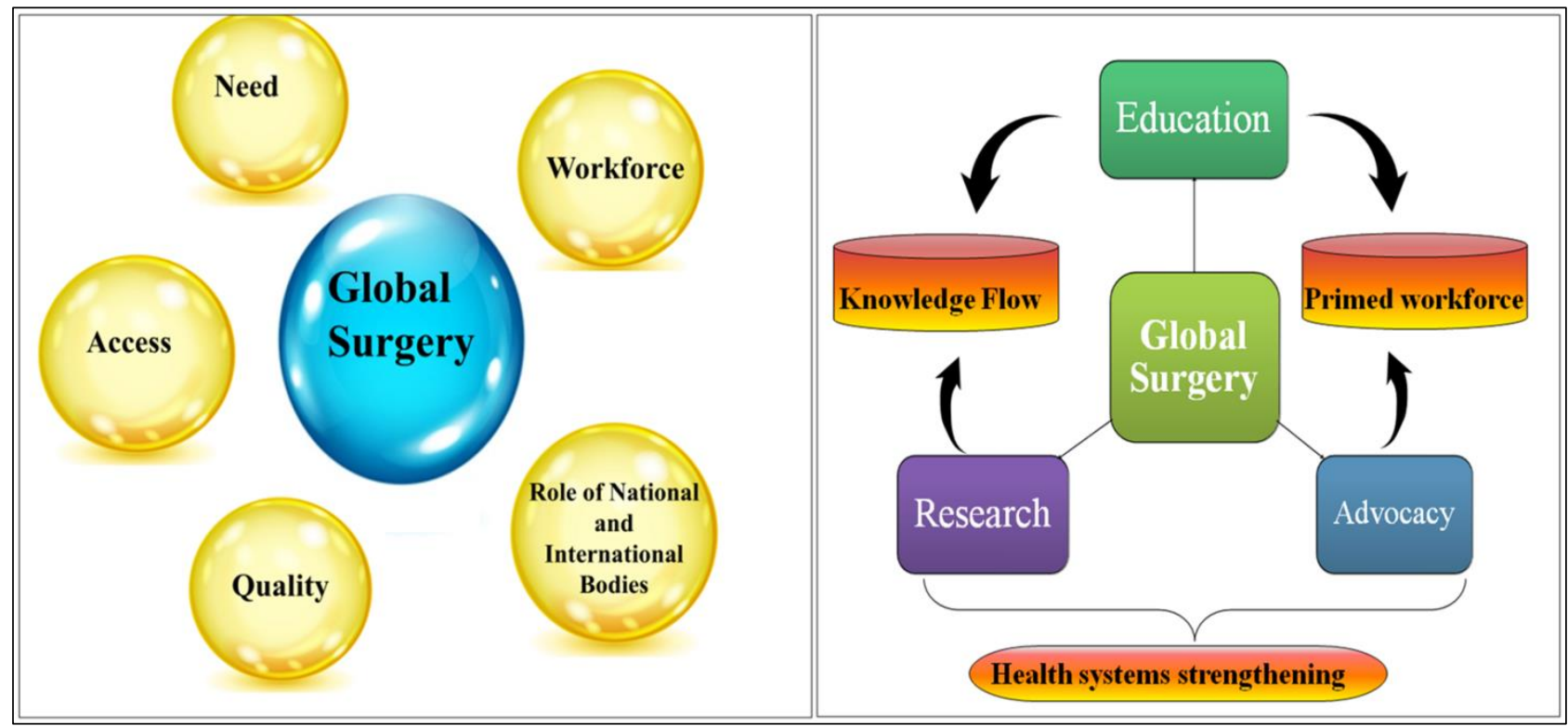

Fig 2: Various facets of Global surgery (left image), interrelations of education, research and advocacy in global surgery (right image). 
Surgical management is part of treatment for a wide variety of treatable diseases, which account for around $30 \%$ of the world's disease burden. Each disease category is still beyond the reach of most of the world's population (Funk LM, Weiser TG, Berry WR, et al. 2010). Although an estimated 266 million operations are carried out worldwide each year (Holmer $\mathrm{H}$, Bekele A, Hagander L, et al. 2019), most of them are confined to high-income countries (HICs), with just $3.5 \%$ of them being the poorest third of the global population (Weiser TG, Regenbogen SE, Thompson KD, et al. 2008). There has been evidence that surgery is needed between regions with a population of around 5625 unmet surgical cases per 100000 in areas such as western sub-Saharan Africa, compared with Australasia and Western Europe that have not had such unmet requirements in comparison (Rose J, Weiser TG, Hider P, et al. 2015). Many surgical subspecialties have shown significant variation in their field of LMICs in unsatisfactory surgical needs (Hung Y- C, Bababekov YJ, Stapleton SM, et al. 2018). From the obstetrical point of view, the cesarean section is now globally the most common operation. However, maternal mortality is most seriously imposed on LMICs (Harrison MS, Goldenberg RL, 2016), where limited availability of safe and timely surgery prevents major complications from being treated (Ologunde R, Vogel JP, Cherian MN, et al. 2014). Even where available, motherhood deaths in LMICs are still 100 times higher following cesarean sections, and approximately one-third of the babies born in these environments will also die (Sobhy S, Arroyo- Manzano D, Murugesu N, et al. 2019). For safe delivery when necessary, timely access to the cesarean section is necessary, with models suggests that maternal death rates will be reduced by 60 percent where LMICs increase their cesarean section to levels suggested in the WHO.

\section{Workforce}

The gap in medical care remains substantial, with an estimated 1.27 million more in 2030 required to achieve minimal surgery densities, based on recent estimates that the number of surgeons, laboratories, and anesthetics in the world was just over 2 million. (National Institute for Health Research Global Health Research Unit, 2019). LMICs are 48\% of the world's population and contain only $18 \%$ of surgeons and $15 \%$ of anesthesiologists worldwide[48], along with significant changes in national distribution. (Bhangu A, Fitzgerald JE and Kolias AG, 2014) With such sparseness, further work is needed to identify areas that need to be most focussed on improvement efforts in national health providers' data (Steyn E and Edge J, 2019).

\section{Training and Education in Global Surgery}

It was surprising found that even after several years of excellent training with a high-income surgical residency program, surgeons were not adequately trained. As a unique and lonely surgeon, residents do not train us to cope with the incredible surgical burden of LMIC disease (Meara JG, Leather AJM, Hagander L, et al. 2015). The shortage of trained surgeons and anesthetics, non-specialist doctors, and non-doctors in low-resort environments often perform surgery tasks, and mid-level training is more and more supportive (Mukhopadhyay S, Lin Y, 
Mwaba P, et al. 2017). These health workers have varying training levels and often facilitate 'task shifts' to offset their skills. Changing tasks can be controversial and not as commonly accepted as other medical fields in surgery, although this can be changed (Taylor S, 2018). In 19 of 52 countries, the previous work on surgical, obstetrical, and anesthetic task shifts was studied in 119 of 147 countries (Mock C, Cherian M, Juillard C, et al. 2010). Increased general surgery, obstetrics, and anesthesia (Shawar YR, Shiffman J and Spiegel DA 2015). Nonetheless, it will be essential to set the limits for transferring tasks and ensuring adequate training and supervision. It will also ensure adequate recognition and remuneration.

\section{Access}

In many environments, the rational geospatial distribution of hospitals and emergency care are rare, with tertiary centers divided between political or academic institutions. In countries with large population spreads, a significant proportion of rural poor and fragmented transport networks, this is particularly problematic (WHO 2015). The number of patients in Tanzania requires a 119-kilometer route to surgery in many such areas is seriously limited, 39 and 74 kilometers for those in Ghana (Citron I, Chokotho L and Lavy C, 2016). To complement this, international efforts are often concentrated in greater urban centers to improve surgical treatment. Surgery is often seen as complex and expensive, potentially reducing its use in global health efforts. The risk of financial hardship remains high worldwide for a single patient following the procedure (Shawar YR, Shiffman J and Spiegel DA. 2015). However, some costeffective surgery economies have been evaluated (Ng- Kamstra JS, Greenberg SLM, Abdullah F, et al. 2016), including those conducted at the regional hospital level (Bhangu A, Fitzgerald JE, Fergusson S, et al. 2014). Surgical therapies are comparable to other standards, such as oral rehydration or antiretroviral therapy, for public health (Reynolds TA, Stewart B, Drewett I, et al. 2017). Work in the 2010 Global Burden of Disease Study has demonstrated that more than one-fifth of the LMIC injury burden could be avoided by treating primary operational care (Wong EG, Gupta S, Deckelbaum DL, et al. 2015).

\section{Quality}

The quality of care is the predominant driver of overall results rather than access (Grimes CE, Bowman KG, Dodgion CM, et al. 2011). The cohort studies of ASOS and GlobalSurg have shown that the perioperative deaths and morbidity in poor resource environments are seven times higher than in high revenues (Ologunde R, Maruthappu M, Shanmugarajah K, et al. 2014). As an indicator of access to safe surgery and anesthesia, (Tansley G, Stewart BT, Gyedu A, et al. 2017) perioperative mortality rates were recommended alongside new tools for measuring the quality of surgical care provided in LMICs (Juran S, Broer PN, Klug SJ, et al. 2018). Several reviews highlight the need for investment in developing the necessary anesthesia infrastructure and workforce and the need to improve existing anesthesias (Mills A, 2014). However, there is a deteriorating status of anesthesia in many countries that consider it non-physicians or technicians, lack of management, and ministerial advocacy that limit efforts to improve anesthesia provision (Penoyar T, Cohen H, Kibatala P, et al. 2012). Fortunately, it 
improves, and the role of anesthesia in the surgical treatment of governmental and nongovernmental organizations is becoming increasingly recognized. Initiatives such as the Global Project Oximetry (GlobalSurg Collaborative, 2018) and the WHO Surgical Safety Checklist, the global framework is working to improve the quality of anesthesia based on evidence; (BM, Madiba TE, Kluyts HL, et al. 2018) in LMICs, use of the WHO checklist is lower; but its impact in reducing 30- day mortality post-emergency laparotomy is more significant than that in HICs.

\section{Role of National and International Bodies}

It is mainly their respective governments that are responsible for populations with surgically treatable diseases (Ologunde R, Vogel JP, Cherian MN, et al. 2014). A resolution was unanimously adopted by the 2015 World Health Assembly and called on its members to recognize this as a key and integral component of universal health coverage (Steyn E and Edge J. 2019). Further work on developing and applying the new National Surgical Obstetric and Anaesthetic Plans (NSOAPs) (Funk LM, Weiser TG, Berry WR, et al. 2010) is proof of their response to this call. This supports an operating system that consists of a three-stage national baseline assessment, facility assessments, and national planning, fully integrated into one national health system (Luboga S, Macfarlane SB, von Schreeb J, et al. 2009). Zambia was the first completed country, with several five NSOAPs launched, with over 20 countries engaged in implementing similar processes (Rose J, Weiser TG, Hider P, et al. 2015). Enhanced standards, enhanced training, and improved medical specialist professional regulations are also international professional championships (Finlayson SRG, 2013), including the College of Surgeons of East, Central and Southern Africa and College of Nursing College of Anesthesiologists for East Central and Southern Africa (Beane A, De Silva AP, Athapattu PL, et al. 2019). A constellation of political, academic, and charitable organizations operating at political, political, and economic levels supports the WHO Global Emergency and Essential Initiative (Park KB, Johnson WD and Dempsey RJ. 2015). In these national and international approaches, the recognition of 'the essential and essential part of healthcare and the advance toward global health coverage' is central. However, this concept cannot survive contact with reality, as clearly expressed in the Lancet Commission (Mock C, Cherian M, Juillard C, et al. 2010). Although system enhancement is usually monitored by name, established system methods and methods are largely absent from global surgery and anesthesia literature. This may contribute to explaining why advocating surgical care is often so difficult (Epiu I, Tindimwebwa JVB, Mijumbi C, et al. 2019). Instead of the clean pathological history, special vertical interventions with easily measurable endpoints, improved surgical management demands a more nuanced understanding of the horizontal system and an appreciation that can mask genuine improvement in specific areas which do not continue to be affected by the general clinic.

\section{Current Situation}


A health care provider includes, but is not limited to, community health workers, hospital management personnel, theater technicians, surgeons, anesthesiologists, and obstetricians (a network of clinicians, surgeon, anesthesiologists, and other non-clinical professionals involved in health care (Ozgediz D, Langer M, Kisa P, et al. 2016). We recognize that operating personnel interdepend, but for the Commission's purpose, our report will focus on an enclosed but crucial workforce element, namely operative, anesthesia, and obstetrics (NIHR Global Health Research Group, 2019). Even people who live near a specialized surgeon can have limited access to surgical and anesthesia care. Only 26 surgeons per 100,000 population served $45 \%$ of Sierra Leonean residents deemed within timely geographical access to specialized surgeons. $2575 \%$ of the country thus lacks adequate access to and access to surgical care. There is little data on clinical outcomes in specialist suppliers, GPs, or clinicians performing similar surgical and anesthetic procedures (Luboga S, Macfarlane SB, von Schreeb J, et al. 2009). Specifications Only one formal meta-analysis (NIHR Global Health Research Unit, 2019) studies have been carried out on obstetric task change. The study showed that mortality was not different, but the researchers were cautious about the results due to the study's design. The majority of published work reports that task shift does not increase mortality or morbidity when a small group of obstetrical, pediatric, and general procedures are carried out.

\section{Future Aspects/Research in Global Surgery}

It is relatively new that both surgery and anesthesia are recognized as critical areas for global health debate. Operational conditions and treatments are not well known as a priority for public health (Galukande M, von Schreeb J, Wladis A, et al. 2010). Public health and infectious diseases have developed a basis for future work. While it is still a relatively early childhood of surgery and anesthesia, on-the-ground studies lead the development of future intervention projects. Currently, there is no clear indication of the future surgery model; it remains uncertain whether financing should be made available in some high-quality clinics that are better linked to transportation or via several clinics in an expanded district hospital model that is more familiar (Dewan MC, Rattani A, Fieggen G, et al. 2018; Sitkin NA, Farmer DL., 2016). New technologies are also uncertain about their role in improving global health but have considerable potential as long as they are affordable, acceptable, and sustainable (P, Darzi A, Yang G- Z, et al. 2012). Clinical academics have traditionally been slow to engage and support the operation's global cause, although this area's importance is recognized now (Finlayson SRG, 2013). In the UK, many research groups with an explicit focus on global surgery receive funding from the National Institute of Health Research (NIHR Global Health Research Unit, 2019; NIHR Global Health Research Group, 2019). In this context, LMIC clinicians, patients, and expert methodologists have been engaged in a recent international Delphi process, focusing on future research in the fields of the unresolved clinical requirement for LMIC surgeons; three priority topics have been identified: the use of surgery, results of the cancer operation and the treatment perioperative care (National Institute for Health Research Global Health Research Unit, 2019). The recent publication of a dedicated global operational question by the British Journal of Surgery reflects this field's growing academic recognition. Global operative cooperation can provide an efficient way to help and train local health workers in research and quality development (Bhangu A, Fitzgerald JE, Fergusson S, et al. 2014; Bhangu A, Fitzgerald 
JE, Kolias AG, 2014). Currently, LMIC research accounts for about $4 \%$ of surgical activity (Steyn E and Edge J, 2019)). However, genuine cooperation can be achieved by promoting locally driven and accessible research and quality improvement (Bashford T and Vercueil A, 2019). This means involving local clinicians in rare or not relevant subjects for high-income clinicians is important in an environment that is resource-efficient (GlobalSurg Collaborative, 2018). To ensure a global comparison of results for certain groups of patients, such as children, 61, addition to an operation-specific research process (NIHR, 2018), a surgical approach such as laparoscopy and surgical intervention is required.

\section{Conclusion}

Global surgery and anesthesia can be regarded as a multidisciplinary undertaking aimed at providing people of the world with better and fair surgery based on the main needs, access, and quality pillars. It deliberately covers disadvantaged areas in other rich countries, and LMICs cover the spectrum of primary research activities through public health and policymaking to direct clinical improvement. This definition is deliberately broad. It focuses not only on theatrical events or attribute ownership to a single clinic provider of either patients or diseases. Still, it calls surgery an integrated pathway within a more wide-ranging health system which requires several elements to work together to provide safe, timely and accessible treatment.

\section{Disclosures:}

- All the authors have contributed to the creation of the submission and grant HPHR permission to review and (if selected) publish their work.

- Authors do not have personal, commercial, academic, or financial interests that influence the research and opinions represented in work submitted to HPHR.

- The submission is NOT under consideration by another publication and/or has not previously been published elsewhere.

\section{Reference}

Bashford T, Vercueil A. Anaesthetic research in low- and middle- income countries. Anaesthesia 2019;74:143-6.

Beane A, De Silva AP, Athapattu PL, et al. Addressing the information deficit in global health: lessons from a digital acute care platform in Sri Lanka. BMJ Glob Health 2019;4:e001134.

Bhangu A, Fitzgerald JE, Fergusson S, et al. Determining universal processes related to best outcome in emergency abdominal surgery: a multicentre, international, prospective cohort study. BMJ Open 2014;4:e006239.

Bhangu A, Fitzgerald JE, Kolias AG. Trainee- led research Collaboratives: a novel model for delivering multi- centre studies. ANZ J Surg 2014;84:902-3. 
Biccard BM, Madiba TE, Kluyts H- L, et al. Perioperative patient outcomes in the African surgical outcomes study: a 7- day prospective observational cohort study. Lancet 2018;391:1589-98.

Citron I, Chokotho L, Lavy C. Prioritisation of surgery in the National health strategic plans of Africa: a systematic review. World J Surg 2016;40:779-83.

Citron I, Meara JG. A global surgery, obstetrics and anaesthesia metamorphosis. Update in Anaesthesia 2019;33.

Dewan MC, Rattani A, Fieggen G, et al. Global neurosurgery: the current capacity and deficit in the provision of essential neurosurgical care. executive summary of the global neurosurgery initiative at the program in global surgery and social change. J Neurosurg 2018;1:1-10.

Epiu I, Tindimwebwa JVB, Mijumbi C, et al. Challenges of anesthesia in low- and middleincome countries: a cross- sectional survey of access to safe obstetric anesthesia in East Africa. Anesth Analg 2017;124:290-9.

Farmer PE, Kim JY. Surgery and global health: a view from beyond the OR. World J Surg;32:533-6.

Finlayson SRG. How should academic surgeons respond to enthusiasts of global surgery? Surgery 2013;153:871-2.

Funk LM, Weiser TG, Berry WR, et al. Global operating theatre distribution and pulse oximetry supply: an estimation from reported data. Lancet 2010;376:1055-61.

Galukande M, von Schreeb J, Wladis A, et al. Essential surgery at the district Hospital: a retrospective descriptive analysis in three African countries. PLoS Med 2010;7:e1000243.

GlobalSurg Collaborative. Laparoscopy in management of appendicitis in high-, middle-, and low- income countries: a multicenter, prospective, cohort study. Surg Endosc 2018;32:3450-66.

GlobalSurg Collaborative. Management and outcomes following surgery for gastrointestinal typhoid: an international, prospective, multicentre cohort study. World J Surg 2018;42:3179-88.

GlobalSurg Collaborative. Mortality of emergency abdominal surgery in high-, middle- and low- income countries. Br J Surg 2016;103:971-88.

GlobalSurg Collaborative. Surgical site infection after gastrointestinal surgery in high- income, middle- income, and low- income countries: a prospective, international, multicentre cohort study. Lancet Infect Dis 2018;18:516-25.

Grimes CE, Bowman KG, Dodgion CM, et al. Systematic review of barriers to surgical care in low- income and middle- income countries. World J Surg 2011;35:941-50.

Harrison MS, Goldenberg RL. Cesarean section in sub- Saharan Africa. Matern Health Neonatol Perinatol 2016;2.

Holmer H, Bekele A, Hagander L, et al. Evaluating the collection, comparability and findings of six global surgery indicators. Br J Surg 2019;106:e138-50.

Howitt P, Darzi A, Yang G- Z, et al. Technologies for global health. Lancet 2012;380:50735.

Hung Y- C, Bababekov YJ, Stapleton SM, et al. Reducing road traffic deaths: where should we focus global health initiatives? J Surg Res 2018;229:337-44.

Juran S, Broer PN, Klug SJ, et al. Geospatial mapping of access to timely essential surgery in sub- Saharan Africa. BMJ Glob Health 2018;3:e000875.

Lavy C, Sauven K, Mkandawire N, et al. State of surgery in tropical Africa: a review. World J Surg 2011;35:262-71.

Lim SS, Vos T, Flaxman AD, et al. A comparative risk assessment of burden of disease and injury attributable to 67 risk factors and risk factor clusters in 21 regions, 1990-2010: a 
systematic analysis for the global burden of disease study 2010. Lancet 2012;380:2224-60.

Luboga S, Macfarlane SB, von Schreeb J, et al. Increasing access to surgical services in subSaharan Africa: priorities for national and international agencies recommended by the Bellagio essential surgery group. PLoS Med 2009;6:e1000200.

Meara JG, Hagander L, Leather AJM. Surgery and global health: a Lancet Commission. Lancet 2014;383:12-13.

Meara JG, Leather AJM, Hagander L, et al. Global surgery 2030: evidence and solutions for achieving health, welfare, and economic development. Lancet 2015;386:569-624.

Mills A. Health care systems in low- and middle- income countries. N Engl J Med 2014;370:552-7.

Mock C, Cherian M, Juillard C, et al. Developing priorities for addressing surgical conditions globally: furthering the link between surgery and public health policy. World J Surg 2010;34:381-5.

Mukhopadhyay S, Lin Y, Mwaba P, et al. Implementing World Health Assembly Resolution 68.15: National surgical, obstetric, and anesthesia strategic plan development-the Zambian experience. Bull Am Coll Surg 2017;102:28-35.

National Institute for Health Research Global Health Research Unit on Global Surgery. Prioritizing research for patients requiring surgery in low- and middle- income countries. Br J Surg 2019;106:e113-20.

Ng- Kamstra JS, Greenberg SLM, Abdullah F, et al. Global surgery 2030: a roadmap for high income country actors. BMJ Glob Health 2016;1:e000011.

NIHR Global Health Research Group on Neurotrauma. Global neurotrauma outcomes study, 2019. Available: http:// neurotrauma. world [Accessed 15 Apr 2019].

NIHR Global Health Research Unit on Global Surgery, 2019. Available: https:// globalsurg. org/ about [Accessed 15 Apr 2019].

NIHR Unit on Global Surgery. Global variation in end stoma formation following left sided colorectal resection. Int J Surg 2018;55:S48-9.

Ologunde R, Maruthappu M, Shanmugarajah K, et al. Surgical care in low and middle- income countries: burden and barriers. Int J Surg 2014;12:858-63.

Ologunde R, Vogel JP, Cherian MN, et al. Assessment of cesarean delivery availability in 26 low- and middle- income countries: a cross-sectional study. Am J Obstet Gynecol 2014;211:504.e1-2.

Ozgediz D, Jamison D, Cherian M, et al. The burden of surgical conditions and access to surgical care in low- and middle- income countries. Bull World Health Organ 2008;86:646-7.

Ozgediz D, Langer M, Kisa P, et al. Pediatric surgery as an essential component of global child health. Semin Pediatr Surg 2016;25:3-9.

Park KB, Johnson WD, Dempsey RJ. Global neurosurgery: the unmet need. World Neurosurg 2016;88:32-5.

Penoyar T, Cohen H, Kibatala P, et al. Emergency and surgery services of primary hospitals in the United Republic of Tanzania. BMJ Open 2012;2:e000369

Raza A, Raza I, Drake TM, et al. The efficiency, accuracy and acceptability of smartphonedelivered data collection in a low- resource setting - A prospective study. Int J Surg 2017;44:252-4.

Reynolds TA, Stewart B, Drewett I, et al. The impact of trauma care systems in low- and middle- income countries. Annu Rev Public Health 2017;38:507-32.

Rose J, Weiser TG, Hider P, et al. Estimated need for surgery worldwide based on prevalence of diseases: a modelling strategy for the who global health estimate. Lancet Glob Health 2015;3 Suppl 2:S13-20. 
Shawar YR, Shiffman J, Spiegel DA. Generation of political priority for global surgery: a qualitative policy analysis. Lancet Glob Health 2015;3:e487-95.

Sitkin NA, Farmer DL. Congenital anomalies in the context of global surgery. Semin Pediatr Surg 2016;25:15-18.

Sobhy S, Arroyo- Manzano D, Murugesu N, et al. Maternal and perinatal mortality and complications associated with caesarean section in low- income and middle- income countries: a systematic review and meta- analysis. Lancet 2019;393:1973-82.

Steyn E, Edge J. Ethical considerations in global surgery. Br J Surg 2019;106:e17-19.

Tansley G, Stewart BT, Gyedu A, et al. The correlation between poverty and access to essential surgical care in Ghana: a Geospatial analysis. World J Surg 2017;41:639-43.

Taylor S.' Global health': meaning what? BMJ Glob Health 2018;3:e000843.

Thomas S, Meadows J, McQueen KAK. Access to cesarean section will reduce maternal mortality in low- income countries: a mathematical model. World J Surg 2016;40:1537-41.

Weiser TG, Regenbogen SE, Thompson KD, et al. An estimation of the global volume of surgery: a modelling strategy based on available data. Lancet 2008;372:139-44.

Wong EG, Gupta S, Deckelbaum DL, et al. Prioritizing injury care: a review of trauma capacity in low and middle- income countries. J Surg Res 2015;193:217-22.

World Health Organization. Global status report on road safety 2015. World Health Organization, 2015. 